\title{
DIE SIN EN SINTAKSIS IN DIE BANTOETALE
}

Waar ek my ten doel stel om in hierdie rede die soeklig op die sin en sintaksis te laat val, wil ek dit voorop stel dat die studie uit die aard van die saak alleen daarop gerig kan wees om die riglyne vir 'n sintaktiese beskrywing vir die Bantoetale te trek, en nie om 'n volledige beskrywing van die tale se sinsbou te gee nie. Die Departement Bantoetale het 'n tweeledige taak, nl. 'n praktiese en 'n akademiese; om die rede is die onderhawige probleem 'n dringende.

Wat die Bantoetale betref, bevind ons ons in die toestand dat die onderdele van die grammatika, die fonetiek, fonologie en morfologie redelik goed uitgewerk en linguisties goed verantwoord is. Die sintaksis of sinsleer daarenteen is nog nie as 'n „Sondergebiet" van die linguistiek behandel nie, inteendeel dit is tot dusver baie stiefmoederlik behandel. Daarbenewens opereer die hendendaagse sinsleer nog met begrippe en uitgangspunte wat linguisties onaanvaarbaar en in die praktyk nie van veel waarde is nie.

Dit is oorbekend dat die beskouinge van Aristoteles en die Stoa via die Latynse grammatika oorgeplant is op die onderskeie volkstale van Europa. Ook die Bantoetale wat eerste deur buitelandse sendelinge bestudeer is, het nie daaraan ontkom nie. Die opstellers van die Bantoe-grammatikas het uitgegaan van die spraakkategorieë wat hulle paslik bevind het en getrag om die minder vormryke Bantoetale soos Latyn te verplooi en volgens die Latynse voorbeeld te beskryf. Daarom bevat die grammatikas van die Bantoetale 'n vormleer wat op die verbuiging- en vervoegingsisteem van die Latynse deklinasie en konjugasie geskoei is. 'n Indeling van die woorde van die Bantoetale na die Latynse partes orationes het hiervoor natuurlik as basis gedien. Dit verbaas ons dus nie dat ook die sinsbeskouing van hierdie groep Bantoetale deurweek is van die klassisisme. Op hierdie tydstip van ons atoomeeu is dit nog steeds Aristoteles wat die toon aangee m.b.t. die sinsbegrip en die beoefening van die sinsleer. Bestudeer ons nou die paar honderd definisies wat daar al van die sin gegee is, bevind ons dat die grootste gros daarvan nog in Aristoteles se verslete mantel gekleed gaan. Die mees verteenwoordigende definisies van die sin lui soos volg: 
Der Satz ist der sprachliche Ausdruck, das Symbol dafür, dass sich die Verbindung mehrerer Vorstellungen oder Vorstellungsgruppen in der Seele des Sprechenden vollzogen hat, und das Mittel dazu, die nämliche Verbindung der nämlichen Vorstellungen in der Seele des Hörenden zu erzeugen. ${ }^{1}$ )

of:

A sentence is an independent group of words which express a complete thought. Every sentence must contain a $\mathrm{subject} \mathrm{(expressed} \mathrm{or} \mathrm{implied)}$ and a predicate. ${ }^{2}$ )

of:

' $n$ Sin is 'n boodskap in taal.

Ook het Doke, die enigste Bantoetaalkundige wat ' $n$ sintaksis aangedurf het, die sin eg tradisioneel soos volg gedefinieer:

A sentence, then, in Zulu, may

be defined as A WORD OR SUCCESSION

OF WORDS EXPRESSING A COMPLETE CONCEPT. $\left.{ }^{3}\right)$

Verder voeg hy hieraan toe:

no concept in Zulu is complete

without its being or containing a predicate. $\left.{ }^{4}\right)$

Genoemde definisies is duidelik variasies van dieselfde tema.

Die ooreenkoms tussen dic beskouinge van Aristoteles en andere m.b.t. die hedendaagse sinsontleding word nog duideliker wanneer sinsontleding gedoen word. Ons ontleed die sin:

Die Bantoes verlang as gevolg van die aanhoudende droogte al vir' $n$ geruime tyd na reën.

Die Bantoes - Onderwerp.

verlang - werkwoordelike gesegde,

as gevolg van die aanhoudende droogte - bywoordelike bepaling van oorsaak,

aanhoudende - byvoeglike bepaling by droogte, al - bywoordelike bepaling by verlang, geruime - byvoeglike bepaling by tyd, na rë̈n - oorsaaklike voorwerp. 
Die term onderwerp is 'n logisistiese term en word gewoonlik gedefinieer as synde daardie sinsdeel waarmee die persoonsvorm in persoon en getal korrespondeer. Daar lê in die begrip nog iets van die oorspronklike inhoud, nl. onderwerp van 'n oordeel van 'n gesprek, want vir Aristoteles was woorde en sinne bloot simbole wat bereikbaar is binne die oordeelsleer. M.a.w. die naamwoord is simbool van 'n onderwerp. Die werkwoord is simbool van 'n predikaat, en die sin is dan simbool van 'n oordeel. Die term bywoordelike bepaling van oorsaak dien ook tot uitdrukking van 'n verhouding nl. tot die werkwoord, daarom ,bywoordelik”, tot benoeming van 'n geval van onderskikking, daarom bepaling. Die term ,oorsaaklike voorwerp" dien weer tot benoeming van 'n verhouding sowel as 'n betekenisverband. Ons stem saam, dat sowel die benoeming van die verhoudinge as die rekenskapgewing van die betekenis vir die begrip van die sin van belang is, maar die vraag is of die juiste interpretasie van die sin met behulp van hierdie metode verkry kan word. Die antwoord is dat deur hierdie metode van sinsontleding die belangrikste sintaktiese kenmerke van die sin buite rekening gelaat word. Die sin word wel min of meer opgebreek in sy samestellende woordgroepe, maar dit word op so 'n wyse gedoen dat dit geen lig werp op die struktuur van die woordgroepe en daarmee ook van die sin nie. Daar is ook nie sprake van die sintaktiese middele wat dien om woordgroepe en sinne te konstitueer nie. Omtrent die woordorde en die sintaktiese funksies wat dit vervul, word niks gerep nie. Die fundamentele probleem: watter tipes van woordgroepe en sintaktiese middele besit die taal onder behandeling? word nie as uitgangspunt van die woordgroepontleding gestel nie. Betekenisse van sinskategorieë en die vorme. daarvoor verskil immers van taal tot taal.

Ewemin word die rangorde van bepalings behandel. Die bepalings van die werkwoord word wel behandel, maar weereens op so 'n wyse dat dit geen lig werp op die struktuur van die onderhawige groepe nie. Persoonlik vereenselwig ek my met die standpunt van De Groot as hy sê:

„Men deelt bv. de ad-verbale bepalingen (d.i. bepalingen van een werkwoord) wel in in ,voorwerpen', bijwoordelijke bepalingen', en ,praedicatieve bepalingen'. Naar de Onderlinge rangorde van deze bepalingen wordt niet of slechts bij de voorwerpen 
gevraagd en bovendien zijn wat men ,praedicatieve bepalingen bij een werkwoord' noemt, niet praedicatieve bepalingen, maar bepalingen in een praedicerende groep." ${ }^{5}$ )

De Groot verklaar voorts dat die bepalings van 'n werkwoord gewoonlik beskryf word as bepalings van die gesegde, d.w.s. van 'n oordeelsvorm, terwyl hulle op presies dieselfde wyse ' $n$ infinitief of ' $n$ participium kan bepaal. Opsommend konstateer ons in die eerste plek, dat daar in hierdie stelsel geen sisteem sit wat die taalstruktuur blootlê nie.

Structuur houdt „ordening” in en ordening kan alleen geschieden volgens bepaalde principen, die zelf ook weer geordend samenhangen, anders ontstaat er geen structuur, maar chaos, sê Reichling. ${ }^{6}$ )

Ten tweede dat hierdie metode van sinsontleding ' $n$ mengelmoes is van sinsleer, psigologie en logika wat voer al rondom die sin en in rigtings verloop wat met linguistiek as sodanig niks te make het nie. Meer nog, hicrvolgens sal aanvaar moet word dat die sin die primêre taaleenheid is en dat die woord alleen by grasie van e.g. bestaan, aangesien een woord alleen nie 'n simbool van ' $n$ oordeel kan wees nie en daarom ook nie 'n logiese denkeenheid daarstel nie. Daarom is die logisisme wat met rededele werk, direk daarvoor verantwoordelik dat 'n aantal linguiste die bestaan van die woord betwyfel. So bv. kom Overdiep se opvatting daarop neer dat die woord nie bestaan nie, want:

Sedert men schrijft, onderscheidt men woorden.7)

Ook John Ries, grondlegger van die moderne sintaksis, koester bedenkinge teen die bestaan van die woord, want sê hy:

sie (lees Wörter) sind künstliche

Einheiten der Grammatik, gewissermassen Abstraktionen

die aus ihrem natürlichen

Zusammenhang herausgelöst sind und für sich allein hein wirkliches Leben haben..$^{8}$ )

'n Mens wonder dan of woorde vir taalgebruik gemaak is of vir die woordeboek. 
Hierdie sinsbeskouing en die sinsontleding wat daaruit ontwikkel is, het vir die student van 'n Bantoetaal baie min praktiese waarde. Ons illustreer met 'n geval: 'n Dosent verduidelik aan 'n student, uit die A-baan, dat 'n sin uit 'n aantal woorde bestaan wat 'n volledige gedagte uitdruk. Daarbenewens moet dit 'n subjek en 'n predikaat bevat, anders is dit ellipties of iets dergeliks. Om te toets of die student goed begryp het wat 'n sin is, kry hy die opdrag om vas te stel hoeveel sinne in 'n gegewe gedrukte paragraaf voorkom. Sonder om hom daaraan te steur watter groepe van woorde 'n volledige gedagte uitdruk, het die student voortgegaan om die hoofletters en punte te tel ten einde die aantal sinne te bepaal. 'n Eenvoudige en praktiese definisie van die sin behoort dus min of meer soos volg te lui:

'n Sin is 'n groep woorde wat met 'n hoofletter aanvang en met 'n punt afsluit.

Daar is ook nog ander praktiese probleme, soos bv. die woordorde van die sin. Verkeerde sinsbou kan nie gekorrigeer word deur te sê dat dit nie goeie Zoeloe is nie. Dit moet gedoen word in ooreenstemming met die struktuur van die sin. 'n Ander baie aktuele probleem is dié van intonasie. Intonasie, soos later aangetoon sal word, maak 'n integrale deel van die Zoeloesin uit. Al gebruik mens die woorde van die Zoeloe- of Tswanasin sintakties en grammaties perfek maar fouteer met die intonasie, dan praat jy Seruti d.i. die taal van die sendeling. Laasgenoemde twee probleme wil ons nie direk aan die logisisme wyt nie, maar met die opmerking volstaan dat sulke struktuurfoute nie met die logisistiese uitgangspunt reggestel kan word nie.

Ons keer terug na Doke se definisie van die sin omdat daarin 'n interessante byvoeging voorkom. Doke maak nl. voorsiening vir die eenwoordsin; want: A sentence may be defined as a word or succession of words, en wat daarop volg. Verder sê hy ook:

Single word sentences are by no means uncommon; for instance Yini? and the reply Yinyoni, each composes a sentence, and each may be treated either morphologically or syntactically. ${ }^{9}$ )

Daar dien gewys te word op die treffende ooreenkoms tussen dic beskouinge van Riẹs en Doke. 
Ries sê die volgende m.b.t. die eenwoordsin: eine grosse Zahl von Sätzen wird bekanntlich durch ein Wort gebildet eine viel zu grosse Zahl. ${ }^{10}$ )

Ries sit opgeskeep met die eenwoordsin, 'n sin bestaan vir hom uit 'n woordverbinding, een woord kan dus nie 'n sin wees nie. Gevolglik stel hy voor dat woorde wat as sinne gebruik kan word in beide die morfologie en die sintaksis behandel moet word. Hiermee het Ries sy hele uitgangspunt m.b.t. sintaksis en die sin omvergegooi.

Doke daarenteen konstateer: apart from the case of the interjectives, no concept in Zulu is complete without its being or containing a predicate. ${ }^{11}$ )

Daar bestaan volgens Doke dus twee soorte eenwoordsinne, t.w. die interjektief en die wat uit 'n werkwoord bestaan. Volgens hom verskil die interjektief van die predikatiewe sin in soverre dit geen subjek bevat of impliseer nie; nogtans is dit vir hom 'n sin, want:

Since the interjective constitutes

a complete concept it may be considered to form a sentence..$^{12}$ )

Doke verduidelik nêrens op watter gronde hy die interjektief as sin beskou nie. Die enigste afleiding waartoe mens kom is dat hy die interjektief as sin beskou, bloot vanweë sy woordsoortelikheid of woordsoortelike karakter. 'n Mens kry die indruk dat die interjektief as woordsoort een of ander sinsvormende eienskappe moet besit wat ander woordsoorte nie het nie, of hoe dan ook. Lg. is nie die geval nie. Van Eeden beweer bv. dat verskillende woordsoorte interjektiwies gebruik kan word.13)

Doke aanvaar voorts op dieselfde gronde dat 'n blote werkwoord 'n sin kan daarstel. Ook die kopulatief sonder aanduiding van enige onderwerp, kan volgens hom 'n sin wees. Ons stem saam, dit is die geval en wil nog hieraan toevoeg dat enige woordsoort as sin gebruik kan word, ook 'n naamwoord. Maar dit wat van ' $n$ woord of woordgroep 'n sin maak is uitsluitlik die intonasie. Ons verduidelik: Die woord hhayi sonder intonasie het geen betekenis nie, terwyl hhayi/- (stygend hoog) nee, beteken. Mhayi met / (stygende) toon beteken, is jy seker? Dic woord yebo - (hoog laag) beteken ja, maar 
yebo /. (stygend laag), beteken, is dit so? Die intonasie gee aan bg. gevalle twee sinsbetekenisse aan dieselfde woord. Dit is ook uitsluitlik die intonasiepatroon wat van die werkwoord $H a m b a$ 'n sin maak. Hamba! d.w.s. interjektiwies uitgespreek, beteken, loop nou; Hamba? met die intonasie van die vraag, beteken, moet ek loop? Betreffende die kopulatief is dit 'n bekende feit dat 'n naamwoord as koppelwerkwoord gebruik kan word bloot deur verlaging van die aanvangstoon van die eerste lettergreep. Umuntu - 'n mens - maar, ngumuntu - dit is 'n mens, en ngumuntu? met vraag, is dit 'n mens? Uit die paar voorbeelde blyk die rol van intonasie al duidelik. Elk van die eenwoordsinne word uitgespreek met die volledige intonasiefiguur wat die sin kenmerk, en geen woord ter wêreld kan sodanige sinne vollediger maak as wat hulle is nie. 'n Logiese afleiding wat ons hieruit maak is dat woorde nie alleen in sinne nie maar ook as sinne gebruik kan word.

Ondersoek het ook aan die lig gebring dat intonasie in Zoeloe ook nog ander funksies vervul, nl. om verskillende sinsoorte van mekaar te onderskei, bv. stelsinne van vraagsinne. Die betekenisonderskeidende funksie wat intonasie verrig, blyk o.m. uit die volgende voorbeelde: Yilihashi lelo. Dit is 'n perd hierdie. Maar, yilihashi lelo? Is dit 'n perd hierdie? UShaka wayebulele abafazi bami. Shaka het my vrouens om die lewe gebring. uShaka wayebulele abafazi bami? Het Shaka my vrouens om die lewe gebring? Uit die voorbeelde blyk dat dit nie die woordlaag is wat die betekenis van die sinne daarstel nie, maar wel die intonasie. Die woordlaag het onveranderd gebly. Die sinsklank vertoon dus semanties verskillende vorme, nl. die bewering, die vraag en die wens. Die probleem hoeveel kategorieë daar werklik bestaan moet nog ondersoek word. Die betekenis en struktuur van die sin kan dus nie in die woordlaag alleen gevind word nie. Die probleem hoe 'n mens sinne moet indeel, is nog altyd verkeerd gestel; die Augenphilologie wat alleen geskrewe sinne analiseer het alleen die betekenis van die woordlaag van die sin op die oog.

Maar die sinsintonasie het verder ook nog 'n wesentlike funksie, d.i. om sinne as sinne te kenmerk en te onderskei van woorde en woordgroepe wat nie sinne is nie, maar onderdele van sinne. Vgl. bv. (z) Ngiyasebenza, ek werk, maar ngiyasebenza... Tswana: Ke a tsamaya, ek loop; maar ke tsamaya..., ek loop... Die laaste sinne van die onderskeie voorbeelde is nie voltooi nie, die intonasie dui dit aan. Omdat woorde en 
woordverbindings altyd in sinne gebruik word, moet elke gesproke woord of woordgroep noodwendig die intonasie van ò ' $n$ volledige sin òf ' $n$ onderdeel van ' $n$ sin òf van ' $n$ onvolledige sin bevat. $\mathrm{Na}$ aanleiding van wat oor intonasie gesê is, lê dit voor die hand dat die sin 'n eenheid van twee dimensies is, t.w. die dimensie of laag van die woord, woorde, woordgroep of woordgroepe en die laag van die intonasie. 'n Sinsdefinisie wat kenmerkend, tiperend en wesentlik van die sin wil wees en ook linguisties wil wees, moet o.a. voorsiening maak vir hierdie twee kategorieë.

Ons wil die sin dan definieer as 'n eenheid van 'n woord, woordgroep of woordgroepe met intonasie. Hierdie definisie verskil heelwat van dié van die logisistiese definisie wat vir elke $\sin$ 'n subjek en 'n predikaat vereis, maar stem baie ooreen met die van De Groot wat lui:

de zin is de klankeenheid voor het gebruik van woorden. ${ }^{14}$ )

De Groot beskou die rol wat intonasie speel egter as allesoorheersend; wanneer hy dus beweer:

Het is dus niet de woordgroep, maar de intonatie, die het karakter, de functie, de betekenis, de linguistische kategorie van de zin bepaalt, ${ }^{15}$ )

kry sy definisie myns insiens ' $n$ te fonologiese karakter.

Laat my toe om hier 'n kort opmerking te maak m.b.t. die interpunksie van Zoeloe, wat myns insiens baie nou saamhang met intonasie. Dit is opvallend dat Zoeloeskrywers van 'n interpunksie gebruik mak wat bots met die intonasiekurwes van die sin. Klaarblyklik bedien die Zoeloeskrywer hom van die interpunksiestelsel van die taal deur medium waarvan hy sy onderrig ontvang het, in die meeste gevalle blyk dit Engels te wees. Die aangeleentheid moet egter nog ondersoek word.

Die sin bestaan ook uit 'n woordlaag. Wanneer 'n sin uit meer as een woord bestaan, en dit is gevoonlik die geval, vorm die woorde 'n woordgroep of woordgroepe wat 'n voltooide sintaktiese struktuur vertoon. Dit is 'n opvallende kenmerk van die woordlaag. Daar bestaan ook baie duidelik 'n onderlinge verband tussen die woorde en woordgroepe wat die sin konstitueer. Reichling sê dat die woorde meesal so gekombineer word dat hulle, ook onafhanklik van die feit dat hulle onder 'n musiese melodie saamgevat word, 'n sintaktiese samehang vertoon. ${ }^{16}$ ) 
Samehang of sintaktiese verband word tussen woordbetekenisse gestig deur sintaktiese middele, waarvan sommige universeel blyk te wees en ander nie. Vir kombinering van woorde tot groepe met 'n bepaalde struktuur en betekenis is dit noodsaaklik dat bepaalde woorde kombinering toelaat; daar bestaan dus ook voorwaardes vir kombinering. Voorwaardes vir kombinering is:

1. Valensie tot neweskikking en

2. valensie tot onderskikking.

\section{Die middele vir kombinering.}

'n Studie van die sintaktiese middele is vir die sintaktikus van kardinale belang. Daar dien op gewys te word dat woordbetekenis geen sintaktiese middel kan wees soos Van der Lubbe beweer nie, aangesien sintaktiese verband juis tussen woordbetekenisse gelê word..$^{17}$ ) Vir my is dit 'n duidelike voorwaarde vir kombinering. Die sintaktiese middele van ' $n$ taal moet minstens ' $n$ aanduiding kan gee van:

1. Watter woorde 'n woordgroep uitmaak, d.w.s. die omvang van die groep aandui,

2. watter woorde lede van die groep is,

3. of die woordgroep neweskikkend of onderskikkend is en

4. wat in 'n onderskikkende groep die kern en wat bepaling is. Induktiewe gegewens dui daarom dat die Bantoetale, dus ook Zoeloe, o.m. oor die volgende middele beskik:

\section{Woordorde:}

Die distribusie van die woorde en woordgroepe t.o.v. mekaar is vir die hoorder 'n aanduiding van hoe die verbande tussen die woorde en woordgroepe gelê word. Hiervolgens is dit ook moontlik om woordgroepe as onderskikkend neweskikkend te erken. Die feit dat in onderskikkende woordgroepe in Zoeloe en Tswana die kern altyd die bepaling vóórafgaan, word kenbaar, bv.

Zoeloe: Umuzi omkhulu, 'n groot stat.

Tswana: Motse ô mogolo, 'n groot stat.

Die normale woonorde in die Zoeloesin is: onderwerp, werkwoord, voorwerp. Bv. Izinkabi zidonsa inqola. Bepalings by die onderwerp sowel as by die voorwerp volg hulle gewoonlik direk, bv. Izinkabi zikababa ezibomvu zidonsa inqola yakhe endala. Predikatiewe bepalings volg na die predikaat of na die 
voorwerp, bv. Izinkabi zidonsa kahle inqola yakhe. Maar die normale orde van die woorde en woordgroepe in die sin kan deur die spreker verander word deur retoriek, of beklemtoning van 'n bepaalde woord of woordgroep. In geval van beklemtoning word die woord wat beklemtoon word aan die begin van die sin geplaas, bv. Inkosi izomema inqina namhlanje word Namhlanje inkosi izomema inqina.

\section{Kongruensie:}

Kongruensie is vir my nog 'n middel tot legging van verband tussen woorde en woordgroepe in die Bantoetale. Die Bantoetale is daarvoor bekend dat bepaalde morfologiese elemente van een woord in 'n woordgroep in die volgende woord van die woordgroep herhaal word. Dit word klasooreenstemming genoem. Reichling sou dit groeperende vormkenmerke noem, bv.:

Zoeloe: Izinkomo zikababa ezinkulu ezinhle zifula entabeni. Tswana: Sebata sêô sê se golo se senya mabele.

\section{Fleksie:}

Morfeme kan aan 'n woord van 'n bepaalde woordklas 'n bepaalde valensie gee aangesien dit die stambetekenis kan modifieer. Die Bantoetale beskik oor heelwat sodanige morfeme soos - ela, - wa, - is a by die werkwoord. In geval van die naamwoord het ons die lokatiewe prefiks esoms $o$ - en die suffiks - ini, om maar net 'n paar te noem.

\section{Toonkurwes:}

Van intonasie is reeds melding gemaak; dit is en bly 'n baie belangrike middel tot realisering van semantiese verband. Die toonkurwes of toonpatrone wat die spreker gebruik, stel die hoorder in staat om woordgroepe te kombineer en te onderskei. Vergelyk die volgende sinne wat uit dieselfde woordmateriaal bestaan maar tog 'n verskil in betekenis vertoon.

Zoeloe: Ngilahlekile, manje angazi ukuthi ngihambe ngaphi maar Ngilahlekile manje, angazi ukuthi ngihambe ngaphi. Tswana: Ngwana/ wa mosetsana wa motho yo. ${ }^{18}$ ) Ngwana wa mosetsana/ wa motho yo. 
Hoewel intonasie ' $n$ baie belangrike rol in die sin speel, kan ons dit nie soos De Groot saam met woordorde as die enigste verbandlegger aanvaar nie. ${ }^{19}$ ) Die middele in die woordlaag is ewe belangrik.

Indien ' $n$ sin dan gedefinieer word as 'n eenheid van 'n woord, woordgroep of woordgroepe met intonasie, dan spreek dit vanself dat sintaksis gedefinieer kan word as:

die leer van die middele waarmee sintaktiese verband tot stand gebring word.

Hiermee vermy ons ook die fout wat Ries begaan, nl. om eers die dissipline te beskryf en daarna die objek te bepaal. ${ }^{20}$ )

Met wat ek $\mathbf{u}$ in die rede voorgehou het, wil ek nie beweer dat alle probleme m.b.t. die sin en sintaksis nou opgelos is nie, maar wil tog in alle beskeidenheid sê dat hierdie benadering vir my meer lig op die probleem werp as die benadering wat tans in swang is.

J. Breed.

P.U. vir C.H.O.

1) M. Paul: Prinzipien der Sprachgeschichte, bl. 121.

2) House and Harman: Descriptive English grammar, bl. 201.

3) C. M. Doke: Zulu Syntax and Idiom, bl. 5.

4) Ibid. bl. 82 .

5) A. W. de Groot: Structurele syntaxis, bl. 115-116.

6) A. Reichling: Verzamelde studies, bl. 44.

7) Overdiep: Moderne Nederlandsche Grammatika, bl. 6.

8) J. Ries: Was ist ein Satz, bl. 60.

9) C. M. Doke: Zulu Syntax and Idiom, bl. 1.

10) J. Ries: Was ist Syntax, bl. 48.

11) C. M. Doke: Zulu Syntax and Idiom, bl. 82.

12) C. M. Doke: Zulu Syntax and Idiom, bl. 163.

13) B. van Eeden: Zoeloe-Grammatika, bl. 534.

14) A. W. de Groot: Structurele Syntaxis, bl. 13.

15) Ibid, bl. 50.

16) A. Reichling: Verzamelde studies, bl. 26.

17) H. F. A. van der Lubbe: Woordvolgorde in het Nederlands, bl. 56.

18) T. M. H. Endemann: Die Gebied en Taak van die Bantoe-Taalkunde, bl. 12.

19) De Groot: Structurele Syntaxis, bl. 50.

20) Vgl. sy drie werke: Was ist Syntax, Wortgruppenlehre? en Was ist ein Satz? 